\title{
TP53 mutations and SNPs as prognostic and predictive factors in patients with breast cancer (Review)
}

\author{
JOANNA HUSZNO $^{1}$ and EWA GRZYBOWSKA ${ }^{2}$ \\ ${ }^{1}$ Outpatient Clinic; ${ }^{2}$ Center for Translational Research and Molecular Biology of Cancer, \\ Maria Skłodowska-Curie Memorial Cancer Center and Institute of Oncology, 44-101 Gliwice, Poland
}

Received October 1, 2017; Accepted February 21, 2018

DOI: $10.3892 / \mathrm{ol} .2018 .8627$

\begin{abstract}
Tumor protein 53 (TP53) is a tumor suppressor gene that encodes tumor protein $\mathrm{p} 53$. Tumor protein $\mathrm{p} 53$ regulates the expression of target genes in response to cellular stress. Additionally, p53 participates in the regulation of cell cycle checkpoints, DNA repair and apoptosis. Mutations in the TP53 gene are associated with numerous types of human cancer, including breast cancer, sarcomas, brain tumors and adrenal cortical carcinomas. In breast cancer, TP53 mutations are a negative prognostic factor. Tumors with TP53 mutations are more likely to be aggressive (triple-negative or human epidermal growth factor receptor 2-positive breast cancer), and resistant to chemotherapy and radiotherapy. In addition to a well-known TP53 mutation, a number of single nucleotide polymorphisms have been systematically identified and evaluated in human populations. In the present article, the role of TP53 mutations and polymorphisms in clinical practice and breast cancer treatment has been described. Additionally, the existing data on TP53 polymorphisms in breast cancer as prognostic and predictive factors have been summarized. A literature search of these topics was performed through PubMed and abstracts of the main cancer congresses in recent years.
\end{abstract}

\section{Contents}

1. Introduction

2. Mechanism of action

3. TP53 mutations in breast cancer

4. Germline TP53 mutations

5. Somatic TP53 mutations

6. TP53 polymorphisms in breast cancer

Correspondence to: Dr Joanna Huszno, Outpatient Clinic, Maria Skłodowska-Curie Memorial Cancer Center and Institute of Oncology, 15 Wybrzeze Armii Krajowej Street, 44-101 Gliwice, Poland

E-mail: joahus@wp.pl

Key words: p53 protein, TP53 mutation, TP53 polymorphisms, breast cancer, prognostic factor
7. Guidelines for examination and screening of patients with TP53 mutations

8. Conclusions

\section{Introduction}

Tumor protein (TP53) is a tumor suppressor gene that encodes tumor protein $\mathrm{p} 53$. The $\mathrm{p} 53$ protein is situated in the cell nuclei and binds directly to DNA. p53 participates in the regulation of cell cycle checkpoints, DNA repair and apoptosis, and regulates the repair process in response to damaging factors, including chemicals, radiation and ultraviolet rays from sunlight. If the DNA is mutated or damaged and cannot be repaired, p53 transmits a signal, which triggers cell apoptosis and prevents cells from dividing and developing into tumors (1).

Inherited TP53 gene mutations (germline mutations) increase the risk of numerous cancer types, including breast cancer, leukemia, sarcomas, central nervous system (CNS) tumors and adrenal cortical cancer [as part of Li-Fraumeni syndrome (LFS)] (2). Certain studies have demonstrated that breast cancer in females with LFS has a positive hormone receptor status and human epidermal growth factor receptor (HER)-2/neu overexpression $(3,4)$. In a previous study, TP53 mutations were observed in $2-3 \%$ of patients with early-onset breast cancer (5). Somatic mutations in TP53 occur in $\sim 40 \%$ of all cases of breast cancer and occur more frequently than inherited mutations (6). In breast cancer, TP53 mutations are a negative prognostic factor (7). Tumors with TP53 mutations are more likely to be aggressive (triple-negative or HER-2-positive breast cancer) $(8,9)$. TP53 mutations occur at an increased frequency in triple-negative breast cancer in comparison with non-triple-negative cancers $(10,11)$. Furthermore, TP53 mutations have been indicated to be associated with chemoresistance $(10,12,13)$.

Additionally, TP53 is also a polymorphic gene. Single nucleotide polymorphisms (SNPs) occur when a single nucleotide is replaced with another, and it is the most common type of change in DNA (14). These changes may affect the function of the p53 protein, and consequently affect cancer risk, progression or response to treatment. Currently, 80 SNPs have been identified in human populations; the majority of SNPs $(90 \%)$ are situated in introns, outside splice sites or in noncoding exons. However, the potential role of SNPs in breast cancer risk remains to be elucidated (15). 
The present study aimed to establish the role of TP53 mutations and polymorphisms in clinical practice and in breast cancer treatment.

\section{Mechanism of action}

TP53 is located on chromosome 17 (17p13.1) and encodes p53, which is a phosphoprotein that is composed of 393 amino acids. p53 consists of four domains: i) a $\mathrm{N}$-terminal sequence (transactivation) domain that is involved in the regulation of the target gene transcription; ii) a core domain that recognizes specific DNA sequences; iii) an oligomerization domain that is responsible for the tetramerization of the protein (the functional form of p53); iv) and a C-terminal domain that is essential for the regulation of p53 activity. The $\mathrm{C}$-terminal domain is modified by kinases, acetylases and glycosylases, and binds with other proteins (16). The transactivation domain is also responsible for interactions with the mouse double minute 2 homolog (MDM2) protein, which has ubiquitin ligase activity and is responsible for controlling the proteasomal degradation of p53 (16).

The p53 protein binds DNA and affects the formation of p21, which interacts with a cell division-stimulating protein (cyclin-dependent kinase 2; CDK-2). When p21 binds with CDK-2, this 2 blocks transition to the next stage of the cell cycle (17). Mutations in TP53 encode proteins that do not have the ability to bind DNA effectively, resulting in uncontrollable cell division and ultimately tumor formation (18).

In healthy cells, the level of $\mathrm{p} 53$ protein remains stable and is regulated by the modulation of p53 degradation. In response to DNA damage and other stress signals, p53 protein expression may increase and affect a number of biological mechanisms, including growth arrest, DNA repair and apoptosis. Under such circumstances, the cell cycle stops, and this prevents the replication of damaged DNA. Furthermore, during growth arrest, p53 activates the transcription of proteins that are involved in DNA repair (19). However, the failure of repair mechanisms, as a result of a defective $\mathrm{p} 53$, may result in the proliferation of abnormal cells and the promotion of cancer (18).

The cellular level of p53 is tightly regulated via the control of protein accumulation and cellular localization (19). The regulation process is performed via covalent modification of the $\mathrm{p} 53$ protein or by interaction with different factors, which causes p53 activation or deactivation in response to stress. A major regulator of p53 is the MDM2 gene, which encodes a specific ubiquitin ligase: MDM2. MDM2 causes the degradation of p53 via the ubiquitin system in proteasomes (20). MDM2 is encoded by a TP53-responsive gene (with TP53 being a transcriptional activator). Phosphorylation of p53 at Ser15, Thr18 or Ser20 disrupts its binding with MDM2 (21). In normal cells, phosphorylation does not occur, and 553 remains at a low level, which is regulated by MDM2. DNA damage activates protein kinases, including ATM serine/threonine kinase, DNA-dependent protein kinase or checkpoint kinase 2, which phosphorylate p53 at one of the three locations: Ser15, Thr18 or Ser20 (21). This causes an increase in the level of p53 and a parallel increase in MDM2 levels, which in turn regulates the total level of p53 protein via a regulatory loop (20). Following DNA damage repair, the ATM serine/threonine kinase is deactivated, resulting in rapid dephosphorylation and destruction of p53 by accumulated MDM2 (20).

\section{TP53 mutations in breast cancer}

Somatic mutations in the TP53 gene are one of the most common genetic abnormalities associated with human cancer. The frequency of TP53 mutations reported in breast tumors ranges between $15-71 \%(22,23)$. Germline TP53 mutations are associated with a predisposition to a wide spectrum of early-onset cancer: LFS and Li-Fraumeni-like syndromes (LFL) (24-26). TP53 mutations were reported at a significantly higher frequency in patients with breast cancer and germline breast and ovarian cancer susceptibility protein 1 (BRCA1) and 2 (BRCA2) mutations $(27,28)$. The most common TP53 mutations are missense substitutions, which occur in $75 \%$ of cases. Other mutations observed in the TP53 gene are frameshift insertions and deletions (9\%), nonsense (7\%) and silent mutations (5\%) (29).

\section{Germline TP53 mutations}

Germline TP53 gene mutations increase the risk of a number of cancer types, including breast cancer, leukemia, soft tissue sarcomas, CNS tumors and adrenocortical cancer (as part of LFS) (30). LFS is an autosomal dominant inherited syndrome that predisposes to development of cancer in affected families. TP53 mutations have been identified in patients with classic LFS (31), LFL (32) or incomplete LFS (33) and in groups of patients with certain cancer types or with multiple tumors (34).

The criteria for classic LFS are as follows: A patient with sarcoma diagnosed at $<45$ years old; a first-degree relative (a parent, sibling or child) with cancer diagnosed at $<45$ years old; and an additional first- or second-degree relative (a grandparent, aunt/uncle, niece/nephew or grandchild) with cancer diagnosed at $<45$ years old or a sarcoma diagnosed at any age (31). In clinical practice, the Chompret criteria are also employed, which helps to identify families with LFS who do not necessarily meet the classic criteria. A diagnosis of LFS can be considered for a patient with a personal and family history that meets 1 of the 3 Chompret criteria (35) (Table I). Other criteria for the diagnosis of LFL have also been described in the literature. The details of the Birch criteria are as follows: A patient with any childhood cancer or sarcoma, brain tumor or adrenocortical carcinoma diagnosed at $<45$ years old; a firstor second-degree relative with a typical Li-Fraumeni cancer (sarcoma, breast cancer, brain tumor, adrenocortical carcinoma or leukemia) at any age; and a first- or second-degree relative with any cancer at $<60$ years old (32). However, LFS (one in 5,000-20,000 individuals) and LFL are rare (36).

The most frequent cancer types observed in carriers of TP53 mutations were breast cancer, soft tissue and bone sarcoma ( $>50 \%$ of tumors), followed by adrenocortical carcinomas and brain tumors $(31,37)$. Other cancer types, including hematological, gastric, colorectal and ovarian cancer, occur earlier in TP53 mutations carriers than in the general population (38). Certain cancer types are observed more rarely than others in TP53 germline mutation carriers, including choroid plexus carcinoma and papilloma (at $<15$ years old), Wilms' tumor and malignant phyllodes tumors (37). 
Table I. Chompret criteria for clinical diagnosis of LFS.

\begin{tabular}{ll}
\hline Criteria & \multicolumn{1}{c}{ Description } \\
\hline 1 & - Presence of a tumor belonging to the LFS tumor spectrum ( $<46$ years old) \\
& $-\geq 1$ first- \\
& - or second-degree family member with a tumor in the LFS tumor spectrum ( $<56$ years old) or with multiple \\
& tumors \\
& - Presence of multiple tumors (non-breast) \\
& - Presence of 2 tumors that belong to the LFS tumor spectrum \\
& - Occurrence of the first tumor in the LFS tumor spectrum at $<46$ years old \\
& - Presence of adrenal cortical carcinoma or a tumor in the choroid plexus, regardless of family history.
\end{tabular}

LFS, Li-Fraumeni syndrome.

A total of $>250$ germline mutations in the TP53 gene have been described $(39,40)$, and the most common germline mutations are missense mutations (77\%). The first mutations that were analyzed were within exons 5-8, which are responsible for encoding the DNA-binding domain of the protein $(37,38)$. Mutations have also been reported outside of the DNA-binding domain. Assumpção et al (41) demonstrated that the TP53 $R 337 \mathrm{H}$ mutation might significantly increase the risk of breast cancer in carriers $(\mathrm{P}=0.0442)$.

\section{Somatic TP53 mutations}

Somatic TP53 gene mutations are present in the majority of human cancer types (6). The most common TP53 mutations are missense substitutions, which occur in $75 \%$ of cases. Other alterations include frameshift insertions and deletions (9\%), nonsense mutations (7\%), silent mutations (5\%) and other infrequent mutations (6). Around 30\% cancer-associated TP53 missense mutations are nucleotide substitutions at highly mutable $\mathrm{CpG}$ dinucleotides, at codons encoding regions essential for the contact between the p53 protein and specific DNA sequences (24). These mutations are associated with the loss of DNA binding activity and transactivation capacity (24). A total of 34 missense mutations that result from transitions at $\mathrm{CpG}$ sites within exons 5-8 have been identified (42). Proteins encoded by the mutated TP53 gene may interfere with wild-type 553 and form hetero-oligomers with a reduced capacity for DNA binding (43).

The value of the TP53 mutation status for predicting tumor response to treatment and patient outcome has been evaluated in numerous cancer types, including breast cancer. The majority of the studies, including large-cohort studies, have demonstrated that TP53 mutations were associated with a poorer prognosis $(6,44)$. The missense and non-missense mutations have a similar prognostic value (reduced outcome) (6). Olivier et al (6) analyzed the clinical value of TP53 somatic mutations in primary breast cancer. In the study, TP53 mutations were most frequent in ductal and medullar cancer with aggressive phenotypes (high histological grade, large size, lymph node metastasis and low hormone receptor expression) and in patients $<60$ years old (6). TP53 mutations within exons 5-8 were associated with an elevated risk of mortality (2.27-fold) in patients with breast cancer (relative risk $>10$ years; $\mathrm{P}<0.0001$ ), compared with patients without mutations. The combination of TP53 mutation and negative progesterone receptor status was associated with worse prognosis. The presence of missense mutations (codon 179 and $\mathrm{R} 248 \mathrm{~W}$ ) may also be associated with a reduced prognosis (43). Certain differences in prognosis have been observed in patients with missense mutations located outside the DNA-binding sites and those with missense mutations located within the DNA-binding sites (6). However, the mechanism underlying this remains unknown. In a large study, TP53 mutations status was revealed to be a risk factor of disease recurrence and mortality in lymph node-negative patients with HER-2-positive tumors (45). In a subsequent trial, the frequency of TP53 mutations was higher in node-positive breast cancer and in tumors that were characterized as invasive ductal carcinoma and of a larger size or with negative steroid receptor status (46). In the univariate analysis, disease-free survival time and overall survival (OS) time were associated with tumor size, lymph node status, histologic degree of anaplasia, steroid receptor status and presence of TP53 mutations (46). In another study, the TP53 mutation status was revealed to be associated with basal-like breast cancer, which characterized by the absence of estrogen receptor $\alpha$ expression, progesterone receptor, HER2 or 'luminal' cytokeratins (CK8/18/19), higher mitotic index and Ki-67 (47).

The role of TP53 mutations as predictive factors has been reported in various types of cancer, including breast cancer. Andersson et al (48) demonstrated that TP53 mutation status was a significant prognostic factor for relapse-free survival time (RFS), breast cancer-corrected survival (BCCS) time and OS time in a group of patients who had received adjuvant cyclophosphamide, methotrexate and 5-fluorouracil (CMF)-based regimens. A poorer overall survival time (OS) for TP53 mutation carriers was also observed in patients treated with CMF $(\mathrm{P}=0.001)$. The TP53 mutation status was also a prognostic factor of borderline significance with regards to BCCS time $(\mathrm{P}=0.05)$ in patients with estrogen receptor-positive status tumors who had received tamoxifen. However, TP53 mutation status was not a significant prognostic indicator of RFS time or OS time in the same group of patients (48). Certain studies have reported that the TP53 mutation status was not a prognostic factor of survival in patients who had received tamoxifen therapy $(49,50)$. 
Furthermore, Bergh et al (51) revealed that adjuvant systemic therapies, including radiotherapy and hormone therapy with tamoxifen, were less effective in patients with TP53 mutations and positive lymph nodes. In other studies, TP53 status has been reported to be a predictive indicator of a poor response to tamoxifen in metastatic disease and a prognostic factor indicator of reduced survival rate following adjuvant therapy with tamoxifen $(52,53)$. Certain preliminary results have reported an association between TP53 mutations and a reduced response to the fluorouracil, Adriamycin and cytoxan chemotherapy regimen (54). In multivariate analysis, patient age, menopause status, disease-free interval, steroid receptor status (estrogen and progesterone) and presence of TP53 mutation were predictive indicators of a poor response to treatment in a tamoxifen-treated group $(\mathrm{P}=0.0014)$. The median PFS time following chemotherapy was reduced for patients with a TP53 mutation compared with those with wild-type TP53 (6.6 and 0.6 months, respectively) (52).

TP53 mutations have been revealed to be associated with an advanced and aggressive tumor phenotype (genomic instability, high mitotic frequency, higher Ki-67 expression and high cyclin E expression). Associations were also reported between TP53 mutations and tumors with larger size, higher disease grade, lymph node metastases and negative estrogen and progesterone receptor status $(55,56)$.

Martinez Bueno et al (57) analyzed data from a phase II trial that compared olaparib [an inhibitor of poly ADP ribose polymerase (PARP)] with a placebo. The patients with TP53 mutations exhibited a statistically significant improvement in OS following the use of olaparib compared with non-carriers (18 and 7.5 months, respectively). In patients with wild-type BRCA genes, only TP53 mutation carriers have been revealed to achieve an improved OS with olaparib (57).

\section{TP53 polymorphisms in breast cancer}

An SNP is defined as a single nucleotide change in a DNA sequence that occurs in $>1 \%$ of the population (15). A SNP is the most common type of change in DNA (15), and the number of SNPs has been systematically identified. However, the clinical consequences of the majority of SNPs remain unknown.

The most frequently reported SNP (SNP72; rs1042522) is a $\mathrm{G} / \mathrm{C}$ variation at the second position of codon 72 in exon 4 , leading to Arg72 or Pro72 protein variants, which serve roles in numerous types of cancer (58). The frequency of SNP72 has been demonstrated to vary among Caucasian, Chinese and African-American patients. The Arg72 variant is more common in Caucasian patients, whilst the Pro72 variant is more frequently detected in Chinese and African-American patients $(59,60)$. Pro72 is located within a proline-rich region and may cause changes in the structure of the SH3-binding domain in the 553 protein. The Pro72 variant induces cell-cycle arrest and DNA repair $(61,62)$. It has also been reported that Arg72 variant is more efficient at inducing apoptosis due to its greater ability to interact with MDM2 than the Pro72 variant (63). In certain studies, polymorphisms in $M D M 2$ and $A K T 1$, which regulate the TP53 pathway, may modify the functions of TP53 $(64,65)$.

Toyama et al (66) reported that the Pro/Pro genotype of TP53 codon 72 may be an independent prognostic factor for patients with breast cancer. In the study, the Pro/Pro genotype was associated with a reduced disease free survival (DFS) compared with other genotypes $(\mathrm{P}=0.049)$, particularly in the subgroup of patients who were treated with adjuvant chemotherapy $(\mathrm{P}=0.009)$. By contrast, in the subgroup of patients treated with adjuvant hormonal therapy or without adjuvant systemic treatment, 72 genotype variants were not associated with DFS.

Another polymorphism (rs2279744; '-410T-G; SNP309; $\mathrm{SNP309T}>\mathrm{G}$ ) is a variant in the promoter of MDM2. The GG genotype of the rs 2279744 polymorphism was associated with the presence of high-grade breast tumors and lymph node metastasis $(P=0.009)(67)$. In another analysis, a SNP in the promoter of MDM2 was associated with the development of LFS at an earlier age and the presence of sporadic cancer (68). The other reported polymorphisms include intron 3 duplication (rs17878362), which has been associated with increased cancer susceptibility, (69) intron 4 SNP (rs1794287) (70) and P47S (rs1800371), which has been associated with apoptosis (71).

\section{Guidelines for examination and screening of patients with TP53 mutations}

The National Comprehensive Cancer Network (NCCN) guidelines for females with LFS and TP53 mutations include breast self-examination from the age of 18 , clinical breast examination every 6-12 months from the age of 20-25 and breast magnetic resonance imaging (MRI) or mammogram from the age of 30 (68). Additionally, the NCCN recommends annual breast MRI with contrast or mammogram from the age of 20 or when breast cancer is diagnosed in cases with a family history of breast cancer prior to the age of 20. Breast cancer examination should start at the age of 18 (67). Annual mammograms and MRI screenings should be performed between 30-75 years (16). Screening of patients $>75$ years old should be based on individual assessment. Patients of both genders with LFS should have annual physical examinations, skin cancer screenings, brain MRIs and colonoscopies every 2-5 years from the age of 25 . Whole body MRIs should also be considered (68). The family history of cancer is also very important and should be recorded. In families with TP53 mutations, the risk of childhood cancer should be assessed (68). The NCCN guidelines recommend testing for TP53 mutations in females with breast cancer diagnosis and are $<35$ years old and without $B R C A 1 / B R C A 2$ mutations. In clinical practice, the NCCN guidelines recommend the option of a risk-reducing mastectomy following discussion regarding TP53 mutations (68). Therapeutic radiotherapy should be used with caution in patients with TP53 mutations due to increased sensitivity to radiation. Breast cancer is the most common tumor type observed in patients with germline TP53 mutations (16).

The National Institute of Clinical Excellence guidelines recommend MRI as a basic examination for female carriers of TP53 mutations that are aged between 20-50 years with a family history of breast cancer (72). Annual mammography for patients $>50$ years old is also recommended (72). Furthermore, the Institute of Cancer Research protocol advises self-examination of breast and annual MRI between the ages of 20-50 years. In addition, it is recommended that 
a review should be undertaken at age 50, and a discussion of risk-reducing mastectomy in TP53 mutation carriers (73).

\section{Conclusions}

Germline mutations in TP53 are associated with a higher risk of breast cancer that is observed in patients with LFS. The presence of TP53 mutations increases the risk of developing certain cancer types (including breast cancer) at a younger age ( $\sim 30$ years) and general lifetime cancer risk. Breast cancer is the most frequently observed tumor type in patients with germline mutations. In a previous study, there was a high frequency of somatic TP53 mutations in patients with a basal-like breast cancer and HER-2-positive tumors or estrogen receptor-negative tumors $(9,68)$. Furthermore, a number of studies have indicated the role of the TP53 mutation as a prognostic factor for the success of chemotherapy, hormonotherapy (in breast cancer) and PARP inhibitors (including olaparib for the treatment of ovarian cancer).

Practice recommendations regarding risk assessment, genetic counseling, breast cancer screening and clinical procedures in TP53 mutation carriers are outlined in the NCCN guidelines for hereditary breast and ovarian cancer. The presence of TP53 mutations may have clinical implications, including decisions on performing mastectomies or therapeutic radiotherapy. In breast cancer, TP53 mutations are an independent marker of a poorer OS time. The role of TP53 mutations and SNPs as predictive factors for the success of chemotherapy and radiotherapy remain under investigation with no clinical indication having been identified thus far.

\section{Acknowledgements}

Not applicable.

\section{Funding}

No funding was received.

\section{Availability of data and materials}

Not applicable.

\section{Authors' contributions}

$\mathrm{JH}$ is responsible for study design, preparation of the manuscript and final approval of the version to be published. ZK performed manuscript correction, provided intellectual content and gave final approval of the version to be published.

\section{Ethics approval and consent to participate}

Not applicable.

\section{Consent for publication}

Not applicable.

\section{Competing interests}

The authors declare that they have no conflict of interest.

\section{References}

1. Tokino $\mathrm{T}$ and Nakamura Y: The role of p53-target genes in human cancer. Crit Rev Oncol Hematol 33: 1-6, 2000.

2. Kratz CP, Achatz MI, Brugières L, Frebourg T, Garber JE, Greer MC, Hansford JR, Janeway KA, Kohlmann WK, $\mathrm{McGee} \mathrm{R}$, et al: Cancer screening recommendations for individuals with Li-Fraumeni syndrome. Clin Cancer Res 23: e38-e45, 2017.

3. Wilson JR, Bateman AC, Hanson H, An Q, Evans G, Rahman N, Jones JL and Eccles DM: A novel HER2-positive breast cancer phenotype arising from germline TP53 mutations. J Med Genet 47: 771-774, 2010.

4. Melhem-Bertrandt A, Bojadzieva J, Ready KJ, Obeid E, Liu DD, Gutierrez-Barrera AM, Litton JK, Olopade OI, Hortobagyi GN, Strong LC and Arun BK: Early onset HER2-positive breast cancer is associated with germline TP53 mutations. Cancer 118: 908-913, 2012.

5. Lalloo F, Varley J, Moran A, Ellis D, O'dair L, Pharoah P, Antoniou A, Hartley R, Shenton A, Seal S, et al: BRCA1, BRCA2 and TP53 mutations in very early-onset breast cancer with associated risks to relatives 1. Eur J Cancer 42: 1143-1150, 2006.

6. Olivier M, Langerød A, Carrieri P, Bergh J, Klaar S, Eyfjord J, Theillet $\mathrm{C}$, Rodriguez $\mathrm{C}$, Lidereau R, Bièche $\mathrm{I}$, et al: The clinical value of somatic TP53 gene mutations in 1,794 patients with breast cancer. Clin Cancer Res 12: 1157-1167, 2006.

7. Varna M, Bousquet G, Plassa LF, Bertheau P and Janin A: TP53 status and response to treatment in breast cancers. J Biomed Biotechnol 2011: 284584, 2011.

8. Wang Y, Helland Å, Holm R, Skomedal H, Abeler VM, Danielsen HE, Tropé CG, Børresen-Dale AL and Kristiansen GB: TP53 mutations in early-stage ovarian carcinoma, relation to long-term survival. Br J Cancer 90: 678-685, 2004.

9. Langerød A, Zhao H, Borgan $\varnothing$, Nesland JM, Bukholm IR, Ikdahl T, Kåresen R, Børresen-Dale AL and Jeffrey SS: TP53 mutation status and gene expression profiles are powerful prognostic markers of breast cancer. Breast Cancer Res 9: R30, 2007.

10. Chae BJ, Bae JS, Lee A, Park WC, Seo YJ, Song BJ, Kim JS and Jung SS: p53 as a specific prognostic factor in triple-negative breast cancer. Jap J Clin Oncol 39: 217-224, 2009.

11. Weisman PS, Ng CK, Brogi E, Eisenberg RE, Won $\mathrm{HH}$, Piscuoglio S, De Filippo MR, Ioris R, Akram M, Norton L, et al: Genetic alterations of triple negative breast cancer by targeted next-generation sequencing and correlation with tumor morphology. Mod Pathol 29: 476-488, 2016.

12. Wattel E, Preudhomme C, Hecquet B, Vanrumbeke M, Ouesnel B, Deryite I, Morel P and Fenaux P: 53 Mutations are associated with resistance to chemotherapy and short survival in hematologic malignancies. Blood 84: 3148-3157, 1994.

13. Børresen-Dale AL: TP53 and breast cancer. Hum Mutat 21: 292-300, 2003.

14. Kato S, Han SY, Liu W, Otsuka K, Shibata H, Kanamaru R and Ishioka $\mathrm{C}$ : Understanding the function-structure and function-mutation relationships of $\mathrm{p} 53$ tumor suppressor protein by high-resolution missense mutation analysis. Proc Natl Acad Sci USA 100: 8424-8429, 2003.

15. National Cancer Institute (NCI): NCI dictionary of cancer terms. https://www.cancer.gov/publications/dictionaries/cancer-terms.

16. Komarova EA, Chumakov PM and Gudcov AV: Molecular genetics of cancer. TP53 in cancer origin and treatment. Edited by Cowell JK 9: 195-221, 2009.

17. Hasty P and Christy BA: p53 as an intervention target for cancer and aging. Pathobiol Aging Age Relat Dis 3: 22702, 2013.

18. National Center for Biotechnology Information: The p53 tumor suppressor protein. Genes and Disease [Internet]. National Center for Biotechnology Information, Bethesda, MD, USA.

19. Sionov RV, Hayon IL and Haupt Y: The regulation of p53 growth suppression. Madame Curie Bioscience Database [Internet]. Landes Bioscience, Austin, TX, 2000-2013.

20. Shi D and Gu W: Dual roles of MDM2 in the regulation of $\mathrm{p} 53$. Ubiquitination dependent and ubiquitination independent mechanisms of MDM2 repression of p53 activity. Genes Cancer 3: 240-248, 2012.

21. Sakaguchi K, Herrera JE, Saito S, Miki T, Bustin M, Vassilev A, Anderson CW and Appella E: DNA damage activates p53 through a phosphorylation-acetylation cascade. Genes Dev 12: 2831-2841, 1998.

22. Hill KA and Sommer SS: p53 as a mutagen test in breast cancer. Environ Mol Mutagen 39: 216-227, 2002. 
23. Pharoah PD, Day NE and Caldas C: Somatic mutations in the p53 gene and prognosis in breast cancer: A meta-analysis. Br J Cancer 80: 1968-1973, 1999.

24. Hainaut P and Hollstein M: p53 and human cancer: The first ten thousand mutations. Adv Cancer Res 77: 81-137, 2000.

25. Malkin D, Li FP, Strong LC, Fraumeni JF Jr, Nelson CE, Kim DH, Kassel J, Gryka MA, Bischoff FZ, Tainsky MA, et al: Germ line p53 mutations in a familial syndrome of breast cancer, sarcomas, and other neoplasms. Science 250: 1233-1238, 1990.

26. Achatz MI, Olivier M, Le Calvez F, Martel-Planche G, Lopes A, Rossi BM, Ashton-Prolla P, Giugliani R, Palmero EI, Vargas FR, et al: The TP53 mutation, R337H, is associated with Li-Fraumeni and Li-Fraumeni-like syndromes in Brazilian families. Cancer Lett 245: 96-102, 2007.

27. Campomenosi P, Monti P, Aprile A, Abbondandolo A, Frebourg T, Gold B, Crook T, Inga A, Resnick MA, Iggo R and Fronza G: p53 mutants can often transactivate promoters containing a p21 but not Bax or PIG3 responsive elements. Oncogene 20: 3573-3579, 2001.

28. Gasco M, Yulug IG and Crook T: TP53 mutations in familial breast cancer: Functional aspects. Hum Mutat 21: 301-306, 2003.

29. Olivier M, Eeles R, Hollstein M, Khan MA, Harris CC and Hainaut P: The IARC TP53 database: New online mutation analysis and recommendations to users. Hum Mutat 19: 607-614, 2002 .

30. Li FP and Fraumeni JF Jr: Soft-tissue sarcomas, breast cancer, and other neoplasms: A familial syndrome? Ann Intern Med 71: 747-752, 1969

31. Li FP, Fraumeni JF Jr, Mulvihill JJ, Blattner WA, Dreyfus MG, Tucker MA and Miller RW: A cancer family syndrome in twenty-four kindreds. Cancer Res 48: 5358-5362, 1998

32. Birch JM, Heighway J, Teare MD, Kelsey AM, Hartley AL, Tricker KJ, Crowther D, Lane DP and Santibáñez-Koref MF: Linkage studies in a Li-Fraumeni family with increased expression of $\mathrm{p} 53$ protein but no germline mutation in $\mathrm{p} 53$. Br $\mathrm{J}$ Cancer 70: 1176-1181, 1994.

33. Brugières L, Gardes M, Moutou $\mathrm{C}$, Chompret $\mathrm{A}$, Meresse V, Matin A, Poisson N, Flamand F, Bonaïti-Pellié C, Lemerie J, et al: Screening for germ line $\mathrm{p} 53$ mutations in children with malignant tumors and a family history of cancer. Cancer Res 53: 452-455, 1993.

34. Varley JM, Evans DG and Birch JM: Li-Fraumeni syndrome-a molecular and clinical review. Br J Cancer 76: 1-14, 1997.

35. Chompret A, Abel A, Stoppa-Lyonnet D, Brugiéres L, Pagés S, Feunteun J and Bonaïti-Pellié C: Sensitivity and predictive value of criteria for p53 germline mutation screening. J Med Genet 38 : 43-47, 2001.

36. Hu H, Liu J, Liao X, Zhang S, Li H, Lu R, Li X, Lin W, Liu M, Xia Z, et al: Genetic and functional analysis of a Li Fraumeni syndrome family in China. Sci Rep 6: 20221, 2016.

37. Olivier M, Hollstein M and Hainaut P: TP53 mutations in human cancers: Origins, consequences, and clinical use. Cold Spring Harb Perspect Biol 2: a001008, 2010.

38. Olivier M, Goldgar DE, Sodha N, Ohgaki H, Kleihues P, Hainaut P and Eeles RA: Li-Fraumeni and related syndromes: Correlation between tumor type, family structure, and TP53 genotype. Cancer Res 63: 6643-6650, 2003.

39. Petitjean A, Mathe E, Kato S, Ishioka C, Tavtigian SV, Hainaut $P$ and Olivier M: Impact of mutant p53 functional properties on TP53 mutation patterns and tumor phenotype: Lessons from recent developments in the IARC TP53 database. Hum Mutat 28 622-629, 2007

40. Leroy B, Fournier JL, Ishioka C, Monti P, Inga A, Fronza G and Soussi T: The TP53 website: An integrative resource center for the TP53 mutation database and TP53 mutant analysis. Nucleic Acids Res 41(Database Issue): D962-D969, 2013.

41. Assumpção JG, Seidinger AL, Mastellato MJ, Ribeiro RC, Zambetti GP, Ganti R, Srivastava K, Shurtleff S, Pei D, Zeferino LC, et al: Association of the germline TP53 R337H mutation with breast cancer in southern Brazil. BMC Cancer 8 : 357, 2008.

42. Petitjean A, Achatz MI, Borresen-Dale AL, Hainaut P and Olivier M: TP53 mutations in human cancers: Functional selection and impact on cancer prognosis and outcomes. Oncogene 26: 2157-2165, 2007

43. Brachmann RK, Vidal M and Boeke JD: Dominant-negative p53 mutations selected in yeast hit cancer hot spots. Proc Natl Acad Sci USA 93: 4091-4095, 1996.

44. Soussi T: The p53 tumor suppressor gene: From molecular biology to clinical investigation. Ann N Y Acad Sci 910: 121-139, 2000.
45. Bull SB, Ozcelik H, Pinnaduwage D, Blackstein ME, Sutherland DAJ, Pritchard KI, Tzontcheva AT, Sidlofsky S, Hanna WM, Qizilbash AH, et al: The combination of p53 mutation and neu/erbB-2 amplification is associated with poor survival in node-negative breast cancer. J Clin Oncol 22: 86-96, 2004.

46. Overgaard J, Yilmaz M, Guldberg P, Hansen LL and Alsner J: TP53 mutation is an independent prognostic marker for poor outcome in both node-negative and node-positive breast cancer. Acta Oncol 39: 327-333, 2000.

47. Miller LD, Smeds J, George J, Vega VB, Vergara L, Ploner A, Pawitan Y, Hall P, Klaar S, Liu ET and Bergh J: An expression signature for $\mathrm{p} 53$ status in human breast cancer predicts mutation status, transcriptional effects, and patient survival. Proc Natl Acad Sci USA 102: 13550-13555, 2005.

48. Andersson J, Larsson L, Klaar S, Holmberg L, Nilsson J, Inganäs M, Carlsson G, Ohd J, Rudenstam CM, Gustavsson B and Bergh J: Worse survival for TP53 (p53)-mutated breast cancer patients receiving adjuvant CMF. Ann Oncol 16: 743-748, 2005.

49. Knoop AS, Bentzen SM, Nielsen MM, Rasmussen BB and Rose C: Value of epidermal growth factor receptor, HER2, p53, and steroid receptors in predicting the efficacy of tamoxifen in high-risk postmenopausal breast cancer patients. J Clin Oncol 19: 3376-3384, 2001

50. Berry DA, Muss HB, Thor AD, Dressler L, Liu ET, Broadwater G, Budman DR, Henderson C, Barcos M, Hayes D and Norton L: HER-2/neu and p53 expression versus tamoxifen resistance in estrogen receptor-positive, node-positive breast cancer. J Clin Oncol 18: 3471-3479, 2000.

51. Bergh J, Norberg T, Sjögren S, Lindgren A and Holmberg L: Complete sequencing of the p53 gene provides prognostic information in breast cancer patients, particularly in relation to adjuvant systemic therapy and radiotherapy. Nat Med 1: 1029-1034, 1995.

52. Berns EM, Foekens JA, Vossen R, Look MP, Devilee P, Henzen-Logmans SC, van Staveren IL, van Putten WL, Inganäs M, Meijer-van Gelder ME, et al: Complete sequencing of TP53 predicts poor response to systemic therapy of advanced breast cancer. Cancer Res 60: 2155-2162, 2000.

53. Powell BL, Bydder S, Grieu F, Gnanasampanthan G, Elsaleh H, Seshadri R, Berns EMJJ and Iacopetta B: Prognostic value of TP53 gene mutation in adjuvant treated breast cancer patients. Breast Cancer Res Treat 69: 65-68, 2001.

54. Clahsen PC, van de Velde CJ, Duval C, Pallud C, Mandarad AM, Delobelle-Deroide A, van den Broek L, Sahmoud TM and van den Vijver: p53 protein accumulation and response to adjuvant chemotherapy in premenopausal women with node-negative early breast cancer. J Clin Oncol 16: 470-479, 1998.

55. Cuny M, Kramar A, Courjal F, Johannsdottir V, Iacopetta B, Fontaine H, Grenier J, Culine S and Theillet C: Relating genotype and phenotype in breast cancer: An analysis of the prognostic significance of amplification at eight different genes or loci and of p53 mutations. Cancer Res 60: 1077-1083, 2000.

56. Thorlacius S, Börresen AL and Eyfjörd JE: Somatic p53 mutations in human breast carcinomas in an Icelandic population: A prognostic factor. Cancer Res 53: 1637-1641, 1993.

57. Martinez Bueno A, Molina MA, Fielding A, Bertran-Alamillo J, Dougherty BA, Lai Z, Hodgson D, Mayo de las Casas C, Rowe P, Gil M, et al: LBA42-Disruptive mutations in TP53 associate with survival benefit in a PARPi trial in ovarian cancer. ESMO, 2017.

58. Dahabreh IJ, Schmid CH, Lau J, Varvarigou V, Murray S and Trikalinos TA: Genotype misclassification in genetic association studies of the rs1042522 TP53 (Arg72Pro) polymorphism: A systematic review of studies of breast, lung, colorectal, ovarian, and endometrial cancer. Am J Epidemiol 177: 1317-1325, 2013.

59. Beckman G, Birgander R, Själander A, Saha N, Holmberg PA, Kivelä A and Beckman L: Is p53 polymorphism maintained by natural selection? Hum Hered 44: 266-270, 1994

60. Langerod A, Burdette L, Yeager M, Presswalla S, et al: Pattern of genetic variation in the tp53 locus indicates linkage disequilibrium extends across the flanking genes, ATP1B2 and WDR79. Hum Mutat (in press), 2006.

61. Pim D and Banks L: p53 Polymorphic variants at codon 72 exert different effects on cell cycle progression. Int J Cancer 108: 196-199, 2004 
62. Siddique M and Sabapathy K: Trp53-dependent DNA-repair is affected by the codon 72 polymorphism. Oncogene 25 : 3489-3500, 2006.

63. Dumont P, Leu JI, Della Pietra AC III, George DL and Murphy M: The codon 72 polymorphic variants of p53 have markedly different apoptotic potential. Nat Genet 33: 357-365, 2003.

64. Bond GL, Hu W, Bond EE, Robins H, Lutzker SG, Arva NC, Bargonetti J, Bartel F, Taubert H, Wuerl P, et al: A single nucleotide polymorphism in the MDM2 promoter attenuates the p53 tumor suppressor pathway and accelerates tumor formation in humans. Cell 119: 591-602, 2004.

65. Harris SL, Gil G, Hu W, Robins H, Bond E, Hirshfield K, Feng Z, Yu X, Teresky AK, Bond G and Levine AJ: Single-nucleotide polymorphisms in the p53 pathway. Cold Spring Harb Symp Quant Biol 70: 111-119, 2005.

66. Toyama T, Zhang Z, Nishio M, Hamaguchi M, Kondo N, Iwase $\mathrm{H}$, Iwata $\mathrm{H}$, Takahashi S, Yamashita $\mathrm{H}$ and Fujii Y: Association of TP53 codon 72 polymorphism and the outcome of adjuvant therapy in breast cancer patients. Breast Cancer Res 9: R34, 2007.

67. Paulin FE, O'Neill M, McGregor G, Cassidy A, Ashfield A, Ali CW, Munro AJ, Baker L, Purdie CA, Lane DP and Thompson AM: MDM2 SNP309 is associated with high grade node positive breast tumours and is in linkage disequilibrium with a novel MDM2 intron 1 polymorphism. BMC Cancer 8: $281,2008$.
68. NCCN Clinical Practice Guidelines in Oncology (NCCN Guidelines(): Genetic/Familial High-Risk Assessment: Breast and Ovarian. Version I. NCCN.org., Fort Washington, DC, 2015.

69. Hu Z, Li X, Qu X, He Y, Ring BZ, Song E and Su L: Intron 3 $16 \mathrm{bp}$ duplication polymorphism of TP53 contributes to cancer susceptibility: A meta-analysis. Carcinogenesis 31: 643-647, 2010.

70. Bellini I, Pitto L, Marini MG, Porcu L, Moi P, Garritano S, Boldrini L, Rainaldi G, Fontanini G, Chiarugi M, et al: DeltaN133p53 expression levels in relation to haplotypes of the TP53 internal promoter region. Hum Mutat 31: 456-465, 2010.

71. Li X, Dumont P, Della Pietra A, Shetler C and Murphy ME: The codon 47 polymorphism in 553 is functionally significant. J Biol Chem 280: 24245-24251, 2005.

72. National Institute for Health and Care Excellence (NICE): Familial breast cancer: classification, care and managing breast cancer and related risks in people with a family history of breast cancer. Clinical guideline [CG164]. NICE, London, 2013. www. nice.org.uk/guidance/cg164. Accessed June 2013.

73. The Institute of Cancer Research (ICR): Division of Genetics and Epidemiology. ICR, London. https://www.icr. ac.uk/our-research/research-divisions/division-of-genetics-andepidemiology. Cancer Genetic Clinical Protocols. 